\title{
Forum
}

\section{How often should general practitioners provide nutrition care to patients? A forecasting activity to determine the target frequency for chronic-disease management in Australia}

Lauren Ball $^{\mathrm{A}, \mathrm{C}}$, Patricia Lee ${ }^{\mathrm{A}}$, Gina L Ambrosini ${ }^{\mathrm{B}}$, Kyra Hamilton $^{\mathrm{A}}$ and Haitham Tuffaha $^{\mathrm{A}}$

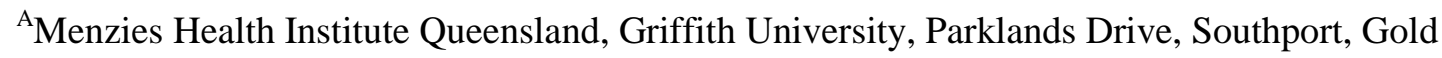
Coast, Qld 4222, Australia.

${ }^{\text {B }}$ School of Population Health, University of Western Australia, Crawley, WA, Australia.

${ }^{\mathrm{C} C o r r e s p o n d i n g ~ a u t h o r . ~ E m a i l: ~ 1 . b a l l @ g r i f f i t h . e d u . a u ~}$

\begin{abstract}
Supporting patients to have healthy dietary behaviours contributes significantly to preventing and managing lifestyle-related chronic diseases. 'Nutrition care' refers to any practice provided by a health professional to support a patient to improve their dietary behaviours and subsequent health outcomes. Approximately 3\% of consultations by Australian general practitioners (GPs) involve the provision of nutrition care. The aim of the present paper was to forecast the potential implications of a higher frequency of nutrition care by GPs. Evidence on the effect of improved dietary behaviours on chronic disease outcomes, number of Australian adults estimated to have poor dietary behaviours and effectiveness of GPs providing nutrition care were taken into consideration. Using hypertension as a case example, for GPs to provide nutrition care to all hypertensive adults who would benefit from improved dietary behaviours, GPs would need to provide nutrition care in a target rate of $4.85 \%$ of consultations or 4.5 million different patients each year. The target aligns with the existing priorities for supporting chronic-disease prevention and management in Australia by increasing the rate that brief lifestyle interventions are provided by primary health professionals. This conservative target presents a considerable challenge for GPs, support staff, researchers and policy makers, but can be used to inform future interventions to support nutrition care by GPs.
\end{abstract}

What is known about the topic?

- General practitioners are able to support patients to have healthy dietary behaviours, which contribute to the prevention and management of chronic disease.

\section{What does this paper add?}

- The present paper provides a conservative target frequency that general practitioners provide nutrition care to patients, so as to facilitate meaningful improvements in health outcomes related to chronic disease.

PY16060

L. Ball et al.

Nutrition care by general practitioners 
Publisher: CSIRO; Journal: PY:Australian Journal of Primary Health

Article Type: research-article; Volume: ; Issue: ; Article ID: PY16060

DOI: 10.1071/PY16060; TOC Head:

Additional keywords: general practice, nutrition therapy, nutritional management, primary care.

\section{Introduction}

Poor dietary behaviour is the most common risk factor for morbidity in Australia, and contributes significantly to the prevalence of lifestyle-related chronic diseases (World Health Organization 2003; Australian Institute of Health and Welfare 2012; Lim et al. 2012). Despite the existence of evidence-based guidelines for healthy eating (National Health and Medical Research Council 2013), it is estimated that most Australian adults have poor dietary behaviours (Australian Institute of Health and Welfare 2012). For example, nearly all (94\%) adults in Australia consume fewer serves of vegetables than recommended and approximately half consume fewer serves of fruit than recommended (Australian Bureau of Statistics 2012; Health and Social Care Information Centre 2014; Moore and Thompson 2015). As a result, the promotion of healthy dietary behaviours is a priority for primary health care, and a key component of best-practice guidelines for primary health professionals (Diabetes Australia and Royal Australian College of General Practitioners 2008; Royal Australian College of General Practitioners 2015). 'Nutrition care’ refers to any practice conducted by a health professional to support a patient to improve their dietary behaviours and subsequent health outcomes (Ball et al. 2010). Nutrition care may include any aspect of nutrition assessment, nutrition advice, nutrition counselling, as well as referral to other nutrition-focused services and health professionals, such as accredited practising dietitians (Ball et al. 2010).

General practitioners (GPs) are recognised as an ideal profession to support patients to improve their dietary behaviours (Ball et al. 2013b). Guidelines for GPs recommend that nutrition care is incorporated into consultations when clinically indicated (Diabetes Australia and Royal Australian College of General Practitioners 2008; Royal Australian College of General Practitioners 2015). Over 90\% of adult general-practice patients are predicted to benefit from improvements in their dietary behaviours (Australian Institute of Health and Welfare 2012), and GPs are capable of providing nutrition care that results in improved dietary behaviours of patients (Ball et al. 2015). However, in Australia, GPs provide nutrition care to patients in $\sim 3 \%$ of consultations (Britt et al. 2015). Clearly, a large practice-evidence gap exists regarding the frequency that GPs provide nutrition care, warranting further attention.

The barriers to GPs providing nutrition care are widely recognised, including lack of time, perceived lack of nutrition knowledge and low self-efficacy (Harris et al. 2012; Ball et al. 2013a). Interestingly, nutrition care has been identified as a significant independent predictor of shorter consultations with GPs in Australia (0.72 min shorter than mean; Britt et al. 2005). Regardless, these barriers have informed educational and workplace initiatives that aim to support GPs to provide nutrition care to patients more regularly (Harris et al. 2005; Edwards 
Publisher: CSIRO; Journal: PY:Australian Journal of Primary Health

Article Type: research-article; Volume: ; Issue: ; Article ID: PY16060 DOI: 10.1071/PY16060; TOC Head:

E et al. 2015; Ball et al. 2016). Evaluations of initiatives for GPs often rely on self-reported practices in line with the procedures of the national annual General Practice Activity Project (Britt et al. 2015). However, these previous initiatives have not specified a target frequency of nutrition care that indicates whether an intervention has been successful in changing practice.

Optimising the frequency of nutrition care provided by GPs has the potential to influence patient health outcomes at an individual and population level. Better understanding the potential effect of increased nutrition care on patient health outcomes will directly inform targets for future initiatives designed to support GPs. Therefore, the aim of the present paper is to forecast the potential implications of a higher frequency of nutrition care by GPs than the current $3 \%$ of consultations. A conservative approach has been taken to inform a feasible target that interventions should aim to achieve in the future.

\section{Why bother? Expected outcomes of improved dietary behaviours}

The implications of poor dietary behaviours are well recognised. For example, with the latest review of the Australian Dietary Guidelines, over 55000 peer-reviewed journal articles including meta-analyses of cohort and randomised controlled trial (RCT) studies were critically reviewed to examine health outcomes associated with various dietary intakes and patterns (National Health and Medical Research Council 2011). The review confirmed that increasing vegetable intake by one serve per day is associated with many improved health outcomes, including a 15-25\% lower risk of coronary heart disease, 25\% lower risk of weight gain and 20\% reduced risk of stroke (Field et al. 2003; He et al. 2006; National Health and Medical Research Council 2011). The review found that for fruit, increasing intake by one serve per day is associated with $7 \%$ lower risk of coronary heart disease, $25 \%$ lower risk of weight gain and 11\% lower risk of stroke (Dauchet et al. 2005; He et al. 2006; National Health and Medical Research Council 2011).

The improvements in health outcomes associated with increased fruit and/or vegetable intake is evident regardless of baseline intake (National Health and Medical Research Council 2011). Furthermore, the benefits continue for each additional serve consumed per day. This is important because strategies that help patients achieve any increase in fruit and/or vegetable intakes will result in meaningful improvements in health outcomes.

\section{Can we do it? Effect of nutrition care provided by GPs}

A systematic review of RCTs has shown that GPs have the potential to facilitate improvements in the dietary behaviours of patients with lifestyle-related chronic diseases (Ball et al. 2013b). Most interventions in the review involved brief nutrition care in standard consultations and observed improvements in the dietary behaviour of participants, such as a reduction of energy consumption of $0.7 \mathrm{MJ} \mathrm{day}^{-1}$ (van der Veen et al. 2002), a reduction in 
Publisher: CSIRO; Journal: PY:Australian Journal of Primary Health

Article Type: research-article; Volume: ; Issue: ; Article ID: PY16060 DOI: 10.1071/PY16060; TOC Head:

excessive alcohol consumption of 36\% (Logsdon et al. 1989), a reduction of meat consumption to three serves or less per week (Sacerdote et al. 2006) and a reduction of fat intake of 5-10\% (Beresford et al. 1997; Ockene et al. 1999; van der Veen et al. 2002). The interventions also observed an increase in fruit and vegetable intake by two serves per week (Sacerdote et al. 2006), an increase in fish intake to at least one serve per week (Sacerdote et al. 2006) and an increase in fibre intake of 0.55 g per $1000 \mathrm{kcal}$ (Beresford et al. 1997). Despite some GPs reporting low self-efficacy in their ability to facilitate behaviour change (Harris et al. 2012; Ball et al. 2013a), this review suggested that an overall positive effect is seen when brief nutrition care is incorporated into consultations.

Enablers to GPs providing nutrition care are less clear, although important to facilitate greater frequency of care. Factors such as increasing nutrition knowledge (Lazarus 1997) and skills (for example, through motivational interviewing training; Edwards E et al. 2015) have been shown to support more favourable attitudes towards providing nutrition care. Early work from the USA has also suggested that there is an increase in the frequency of nutrition care by providing greater training to GPs (Lazarus 1997), warranting greater attention to these enablers.

\section{Hypertension as a case study}

Hypertension is a significant risk factor for coronary heart disease and other cardiovascular conditions, which can be prevented and managed through healthy lifestyle behaviours, including healthy dietary behaviours (World Health Organization 2003). The prevalence of hypertension is approximately one-third (31.6\%) of Australian adults (Australian Bureau of Statistics 2012). Furthermore, hypertension is the most common 'problem' managed by Australian GPs, at 7.9 occurrences per 100 consultations (Britt et al. 2015). With over 89 million consultations provided by GPs each year, this equates to nearly 7 million consultations that include care for a patient with hypertension. Nutrition care is estimated to currently occur in 3\% of consultations provided by Australian GPs (Britt et al. 2015). Assuming the frequency of nutrition care provided to patients with hypertension is similar to those without hypertension, this equates to 210000 consultations per year.

In a dietary-intervention study, where patients with hypertension (baseline systolic and diastolic blood pressure $131.3 \pm 10.8$ and $84.7 \pm 4.7 \mathrm{~mm}$ Hg respectively) were provided with low-sodium foods for 3 weeks; systolic blood pressure reduced by an average of $11.4 \mathrm{~mm} \mathrm{Hg}$ and diastolic blood pressure reduced by an average of $5.5 \mathrm{~mm} \mathrm{Hg}$ (Appel et al. 1997). However, in practice, the expected outcome of providing brief, structured nutrition care in one consultation is a reduction in diastolic blood pressure of $4.0 \mathrm{~mm}$ Hg over 12 months (from 89.7 to 85.7 mm Hg; $P=0.001$; Salkeld et al. 1997; Ball et al. 2013b). This is an 
Publisher: CSIRO; Journal: PY:Australian Journal of Primary Health

Article Type: research-article; Volume: ; Issue: ; Article ID: PY16060 DOI: 10.1071/PY16060; TOC Head:

important finding because the high-quality Framingham heart study demonstrated that even smaller reductions ( $2.0 \mathrm{~mm} \mathrm{Hg}$ ) in population-wide diastolic blood pressure is associated with an estimated $17 \%$ reduction in the prevalence of hypertension, and $6 \%$ reduction in risk of coronary heart disease (Cook et al. 1995). Collectively, this suggests that GPs facilitating meaningful reductions in blood pressure at an individual level have the potential to contribute to population-wide health improvements.

\section{How much is enough? Effect of different frequencies of nutrition care}

To prevent and manage chronic disease, GPs would ideally provide nutrition care to all adult patients with poor dietary behaviours, estimated at $94 \%$ of consultations. This is based on the estimated number of adults in Australia who consume fewer serves of vegetables than recommended (Australian Bureau of Statistics 2014). Given that $~ 80 \%$ of consultations are with adult patients, this would mean an overall frequency of $74 \%$ of consultations if nutrition care for adolescents or children is excluded. Presuming the total number of consultations provided by GPs remains constant, this target is nearly 25 times more frequent than the current rate of nutrition care, and is unlikely to be achievable in the short- to medium-term future.

An alternative approach focusing on secondary prevention is to consider the provision of nutrition care for a common condition, such as the previous case example of hypertension. On the basis of (i) the total Australian population (23.13 million), (ii) the proportion of adults who consult a GP at least once per year (84\%; Britt et al. 2015) and (iii) the proportion of adult patients in general practice (80\%; Britt et al. 2015), 15.5 million Australian adults receive care from a GP each year. Given that the prevalence of hypertension is currently $31.6 \%$, this equates to 4.9 million Australian adults with hypertension. If $94 \%$ of Australian adults are estimated to have poor dietary behaviours, then 4.5 million adults with hypertension would benefit from receiving nutrition care from a GP at least once per year.

Fig. 1 displays the number of people who would receive nutrition care on the basis of the frequency of provision by GPs. The figure provides a conservative assumption that nutrition care is provided to different patients (rather than the same patient multiple times per year). The shaded section outlines the difference in reach between the current frequency of nutrition care, and the nutrition care required to reach 4.5 million adults. On the basis of these calculations, the target frequency is $\sim 4.85 \%$ of consultations, an increase of $1.85 \%$ on the current rate of $3 \%$. On the basis of the previous outcomes observed from nutrition care, this could reduce the prevalence of hypertension by $17 \%$ (Cook et al. 1995), which equates to over 735000 fewer Australians with high blood pressure. This potential effect is clearly worthy of attention. The target does not account for other sources of nutrition care, such as 
Publisher: CSIRO; Journal: PY:Australian Journal of Primary Health

Article Type: research-article; Volume: ; Issue: ; Article ID: PY16060

DOI: 10.1071/PY16060; TOC Head:

from allied health professionals and non-health professional sources, highlighting potential for further support provided to be available to patients.

\section{What now? The need for support to change}

Consideration of strategies grounded in sound behavioural theory to support GPs to provide nutrition care is a timely and important line of investigation (Ball et al. 2013a, 2015). A target of providing nutrition care in $4.85 \%$ of consultations with hypertensive patients presents an important and potentially considerable challenge for GPs and support staff. The target aligns with the priorities for supporting chronic-disease prevention and management by increasing the rate that brief lifestyle interventions are provided by primary health professionals (National Preventative Health Taskforce 2008). Importantly, this target accounts for only brief nutrition care provided to individual patients in consultations and does not account for secondary factors such as low socioeconomic status or low health literacy that are also associated with poor dietary behaviours. Therefore, public health nutrition interventions are still required in additional to supporting GPs to provide nutrition care.

On the basis of existing evidence, achieving the target frequency of nutrition care will (i) improve dietary behaviours of adults, (ii) reduce patient risk of developing a chronic disease (namely hypertension in this example), (iii) improve health outcomes associated with chronic disease (such as weight, glycaemic control and blood pressure) and (iv) reduce preventable hospital admissions and mortality. This target should be used by GPs, support staff, researchers and policy makers to inform future strategies in this area.

\section{Conclusions}

The importance of nutrition care to support improved dietary behaviours is well recognised. A large practice-evidence gap exists regarding the frequency that GPs provide nutrition care, which is currently estimated at $3 \%$ of consultations. Optimising the frequency of nutrition care provided by GPs has the potential to influence patient health outcomes at an individual and population level. This forecasting activity provides a conservative target frequency (4.85\% of consultations) that GPs provide nutrition care to patients with hypertension so as to facilitate meaningful improvements in health outcomes related to chronic disease. Although achieving this target may present as a considerable challenge for GPs and support staff, it can be used to inform future strategies in this area so as to improve patient health outcomes.

\section{References}

<jrn>Appel LJ, Moore TJ, Obarzanek E, Vollmer WM, Svetkey LP, Sacks FM, Bray GA, Vogt TM, Cutler JA, Windhauser MM, Lin PH, Karanja N (1997) A clinical trial of the effects of dietary 
Publisher: CSIRO; Journal: PY:Australian Journal of Primary Health

Article Type: research-article; Volume: ; Issue: ; Article ID: PY16060 DOI: 10.1071/PY16060; TOC Head:

patterns on blood pressure. DASH Collaborative Research Group. The New England Journal of

Medicine 336, 1117-1124. doi:10.1056/NEJM199704173361601</jrn>

<eref>Australian Bureau of Statistics (2012) Australian health survey: first results. Available at

www.abs.gov.au/ausstats/abs [Verified August 2016]</eref>

$<$ unknown>Australian Bureau of Statistics (2014) Australian health survey: nutrition first results. $</$ unknown $>$

<bok>Australian Institute of Health and Welfare (2012) Risk factors contributing to chronic disease.

Australian Government, Canberra. $</$ bok $>$

<jrn>Ball L, Hughes R, Leveritt M (2010) Nutrition in general practice: role and workforce preparation expectations of medical educators. Australian Journal of Primary Health 16, 304-310. doi:10.1071/PY10014</jrn>

<jrn>Ball L, Hughes R, Leveritt M (2013a) Health professionals’ views of the effectiveness of nutrition care in general practice setting. Nutrition \& Dietetics: the Journal of the Dietitians Association of Australia 70, 35-41. doi:10.1111/j.1747-0080.2012.01627.x</jrn>

<jrn>Ball L, Johnson C, Desbrow B, Leveritt M (2013b) General practitioners can offer effective nutrition care to patients with lifestyle related chronic disease: a systematic review. Journal of Primary Health Care 5, 59-69.</jrn>

<jrn>Ball L, Leveritt M, Cass S, Chaboyer W (2015) Effect of nutrition care provided by primary health professionals on adults' dietary behaviours: a systematic review. Family Practice 32, 605617. $</ \mathrm{jrn}>$

<jrn>Ball L, Ball D, Leveritt M, Ray S, Collins C, Patterson E, Ambrosini G, Lee P, Chaboyer W (2016) Using logic models to enhance the methodological quality of primary health care interventions: guidance from an intervention to promote nutrition care by general practitioners and practice nurses. Family Practice. $</$ jrn $>$

$<$ jrn>Beresford S, Curry S, Kristal A, Lazovich D, Feng Z, Wagner E (1997) A dietary intervention in primary care practice: the eating patterns study. American Journal of Public Health 87, 610-616. doi:10.2105/AJPH.87.4.610</jrn>

$<$ jrn>Britt H, Valenti L, Miller G (2005) Determinants of consultation length in Australian general practice. The Medical Journal of Australia 183, 68-71.</jrn>

<bok>Britt H, Miller G, Henderson J, Charles J, Valenti L, Harrison C, Bayram C, Zhang C, Pollack A, O’Halloran J, Pan Y (2015) General practice activity in Australia 2014-15. General practice series number 34. Canberra. $</$ bok $>$

$<$ jrn>Cook N, Cohen J, Hebert P, Taylor J, Hennekens C (1995) Implications of small reductions in diastolic blood pressure for primary prevention. Archives of Internal Medicine 155, 701-709. doi:10.1001/archinte.1995.00430070053006 </jrn> 
Publisher: CSIRO; Journal: PY:Australian Journal of Primary Health

Article Type: research-article; Volume: ; Issue: ; Article ID: PY16060 DOI: 10.1071/PY16060; TOC Head:

$<$ jrn>Dauchet L, Amouyel P, Dallongeville J (2005) Fruit and vegetable consumption and risk of stroke: a meta-analysis of cohort studies. Neurology 65, 1193-1197. doi:10.1212/01.wnl.0000180600.09719.53</jrn>

$<$ bok>Diabetes Australia and Royal Australian College of General Practitioners (2008) 'Diabetes Management in General Practice’, 14th edn. (Sydney) $</$ bok $>$

$<$ jrn>Edwards E, Stapleton P, Williams KLB (2015) Building skills, knowledge and confidence in eating and exercise behaviour change: brief motivational interviewing training for healthcare providers. Patient Education and Counseling 98, 674-676. doi:10.1016/j.pec.2015.02.006</jrn>

<jrn>Field AE, Gillman MW, Rosner B, Rockett HR, Colditz GA (2003) Association between fruit and vegetable intake and change in body mass index among a large sample of children and adolescents in the United States. International Journal of Obesity and Related Metabolic Disorders 27, 821-826. doi:10.1038/sj.ijo.0802297<<jrn>

<jrn>Harris MF, Hobbs C, Davies GP, Simpson S, Bernard D, Stubbs A (2005) Implementation of a SNAP intervention in two divisions of general practice: a feasibility study. The Medical Journal of Australia 183, S54-S58.</jrn>

<jrn>Harris MF, Fanaian M, Jayasinghe UW, Passey M, Lyle D, McKenzie S, Davies GP (2012) What predicts patient-reported GP management of smoking, nutrition, alcohol, physical activity and weight? Australian Journal of Primary Health 18, 123-128. doi:10.1071/PY11024</jrn>

$<$ jrn>He FJ, Nowson CA, MacGregor GA (2006) Fruit and vegetable consumption and stroke: metaanalysis of cohort studies. Lancet 367, 320-326. doi:10.1016/S0140-6736(06)68069-0</jrn>

$<$ eref $>$ Health and Social Care Information Centre (2014) Health survey for England - 2013 [NS]. Available at http://www.hscic.gov.uk/catalogue/PUB16076 [Verified]</eref>

<jrn>Lazarus K (1997) Nutrition practices of family physicians after education by a physician nutrition specialist. The American Journal of Clinical Nutrition 65, S2007-S2009.</jrn>

<jrn>Lim SS, Vos T, Flaxman AD, Danaei G, Shibuya K, Adair-Rohani H, AlMazroa MA, Amann M, Anderson HR, Andrews KG, Aryee M, Atkinson C, Bacchus LJ, Bahalim AN, Balakrishnan K, Balmes J, Barker-Collo S, Baxter A, Bell ML, Blore JD, Blyth F, Bonner C, Borges G, Bourne R, Boussinesq M, Brauer M, Brooks P, Bruce NG, Brunekreef B, Bryan-Hancock C, Bucello C, Buchbinder R, Bull F, Burnett RT, Byers TE, Calabria B, Carapetis J, Carnahan E, Chafe Z, Charlson F, Chen H, Chen JS, Cheng AT-A, Child JC, Cohen A, Colson KE, Cowie BC, Darby S, Darling S, Davis A, Degenhardt L, Dentener F, Des Jarlais DC, Devries K, Dherani M, Ding EL, Dorsey ER, Driscoll T, Edmond K, Ali SE, Engell RE, Erwin PJ, Fahimi S, Falder G, Farzadfar F, Ferrari A, Finucane MM, Flaxman S, Fowkes FGR, Freedman G, Freeman MK, Gakidou E, Ghosh S, Giovannucci E, Gmel G, Graham K, Grainger R, Grant B, Gunnell D, Gutierrez HR, Hall W, Hoek HW, Hogan A, Hosgood HD III, Hoy D, Hu H, Hubbell BJ, Hutchings SJ, Ibeanusi SE, Jacklyn GL, Jasrasaria R, Jonas JB, Kan H, Kanis JA, Kassebaum N, Kawakami N, Khang Y-H, Khatibzadeh S, Khoo J-P, Kok C, Laden F, Lalloo R, Lan Q, Lathlean T, Leasher JL, Leigh J, Li Y, 
Publisher: CSIRO; Journal: PY:Australian Journal of Primary Health

Article Type: research-article; Volume: ; Issue: ; Article ID: PY16060 DOI: 10.1071/PY16060; TOC Head:

Lin JK, Lipshultz SE, London S, Lozano R, Lu Y, Mak J, Malekzadeh R, Mallinger L, Marcenes W, March L, Marks R, Martin R, McGale P, McGrath J, Mehta S, Memish ZA, Mensah GA, Merriman TR, Micha R, Michaud C, Mishra V, Hanafiah KM, Mokdad AA, Morawska L, Mozaffarian D, Murphy T, Naghavi M, Neal B, Nelson PK, Nolla JM, Norman R, Olives C, Omer SB, Orchard J, Osborne R, Ostro B, Page A, Pandey KD, Parry CDH, Passmore E, Patra J, Pearce N, Pelizzari PM, Petzold M, Phillips MR, Pope D, Pope CA III, Powles J, Rao M, Razavi H, Rehfuess EA, Rehm JT, Ritz B, Rivara FP, Roberts T, Robinson C, Rodriguez-Portales JA, Romieu I, Room R, Rosenfeld LC, Roy A, Rushton L, Salomon JA, Sampson U, Sanchez-Riera L, Sanman E, Sapkota A, Seedat S, Shi P, Shield K, Shivakoti R, Singh GM, Sleet DA, Smith E, Smith KR, Stapelberg NJC, Steenland K, Stöckl H, Stovner LJ, Straif K, Straney L, Thurston GD, Tran JH, Van Dingenen R, van Donkelaar A, Veerman JL, Vijayakumar L, Weintraub R, Weissman MM, White RA, Whiteford H, Wiersma ST, Wilkinson JD, Williams HC, Williams W, Wilson N, Woolf AD, Yip P, Zielinski JM, Lopez AD, Murray CJL, Ezzati M (2012) A comparative risk assessment of burden of disease and injury attributable to 67 risk factors and risk factor clusters in 21 regions, 1990-2010: a systematic analysis for the global burden of disease study 2010. Lancet 380, 2224-2260. doi:10.1016/S0140-6736(12)61766-8 $</ j r n>$

$<$ jrn>Logsdon D, Lazaro C, Meier R (1989) The feasibility of behavioral risk reduction in primary medical care. American Journal of Preventive Medicine 5, 249-256. </jrn>

$<$ jrn>Moore LV, Thompson FE (2015) Adults meeting fruit and vegetable intake recommendations: United States, 2013. MMWR. Morbidity and Mortality Weekly Report 64, 709-713.</jrn> $<$ bok> National Health and Medical Research Council (2011) A review of the evidence to address targeted questions to inform the revision of the Australian dietary guidelines. Australian Government, Canberra. $</$ bok $>$

$<$ bok> National Health and Medical Research Council (2013) Australian dietary guidelines.

Canberra. $</$ bok $>$

<other>National Preventative Health Taskforce (2008) Australia: the healthiest country by 2020.

Discussion paper. Chapter 2: obesity in Australia. Commonwealth of Australia, Canberra.</other>

<jrn>Ockene I, Hebert J, Ockene J, Saperia G, Stanek E, Nicolosi R, Merriam P, Hurley T (1999)

Effect of physician-delivered nutrition counseling training and an office support program on saturated fat intake, weight, and serum lipid measurements in a hyperlipidemic population: Worcester area trial for counseling in hyperlipidemia (WATCH). Archives of Internal Medicine 159, 725-731. doi:10.1001/archinte.159.7.725</jrn>

<bok>Royal Australian College of General Practitioners (2015) 'Smoking, Nutrition, Alcohol and Physical Activity (SNAP): a Population Health Guide to Behavioural Risk Factors in General Practice', 2nd edn. (Melbourne) $<$ /bok $>$

<jrn>Sacerdote C, Fiorini L, Rosato R, Audenino M, Valpreda M, Vineis P (2006) Randomized controlled trial: effect of nutritional counselling in general practice. International Journal of Epidemiology 35, 409-415. doi:10.1093/ije/dyi170</jrn> 
Publisher: CSIRO; Journal: PY:Australian Journal of Primary Health

Article Type: research-article; Volume: ; Issue: ; Article ID: PY16060 DOI: 10.1071/PY16060; TOC Head:

<jrn>Salkeld G, Phongsavan P, Oldenburg B, Johannesson M, Convery P, Graham-Clarke P, Walker

S, Shaw J (1997) The cost-effectiveness of a cardiovascular risk reduction program in general

practice. Health Policy (Amsterdam) 41, 105-119. doi:10.1016/S0168-8510(97)00015-8</jrn>

<jrn>van der Veen J, Bakx C, van den Hoogen H, Verheijden M, van den Bosch W, van Weel C, van

Staveren W (2002) Stage-matched nutrition guidance for patients at elevated risk for cardiovascular

disease: a randomized intervention study in family practice. Family Practice 51, 751-758.</jrn>

<bok>World Health Organization (2003) WHO technical report series: diet, nutrition, and the

prevention of chronic diseases. Geneva. $</$ bok $>$

Received 15 May 2016, accepted 9 August 2016

Fig. 1. Reach of nutrition care to patients with hypertension on the basis of frequency of provision by general practitioners. Calculations are based on data from (Britt et al. 2014). 